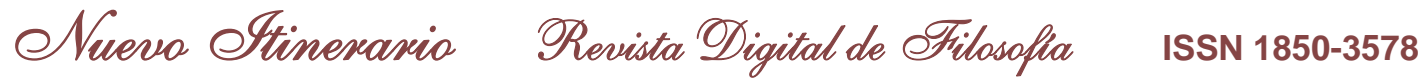

\section{La concepción contemporánea del trabajo en una encrucijada ${ }^{1}$}

Javier R. Alegre*

En este artículo escribo sobre el trabajo. Aclaro que lo hago porque me resulta mucho más fácil escribir sobre, que trabajar. Es más, conozco a alguien que me confesó que estudió filosofía porque le parecía la manera más elegante y sutil de no trabajar -y sino, que me desmientan los antiguos griegos, agregó-.

Esta humorada inicial tiene por objetivo explicitar ciertos preconceptos y situarnos en lo que es mi objetivo: reflexionar acerca del concepto de trabajo y las implicaciones que posee para la vida humana. Si usted pudo entender el chascarrillo es porque existe una visión en la que pensar no es una actividad que merezca ser incluida dentro del rubro trabajo; esta concepción está emparentada con el industrialismo del siglo XIX y continúa presente en algunos sectores de la población. Pero aunque la mayoría de los lectores de una revista especializada en filosofía como ésta no comparta este punto de vista -entre otras razones porque nos deja mal parados ante los ojos de los demás a quienes realizamos tareas intelectuales-, se volvería mucho más difícil lograr un consenso afirmativo si alguien sostuviera que un individuo está trabajando cuando, por ejemplo, lee y reflexiona solo en su casa, sin estar al amparo de una organización, sin recibir retribución monetaria por ello y sin estar sujeto a horario alguno -por pura voluntad o placer diríamos-. Este segundo enfoque sobre cuáles son las características que delimitan aquello que es trabajo de lo que no es, tiene que ver con las condiciones socio-económico-laborales de la última mitad del siglo XX y es el imperante en la actualidad.

Bien, lo que hago a partir de aquí es analizar el contexto en que surgieron estos dos conceptos del trabajo, presentar las características que cada uno posee y extraer las consecuencias que trajeron y traen para los seres humanos; para luego, ya en la parte final, esbozar alternativas a los problemas que plantea la concepción vigente -dificultades que son cada vez más patentes-. En este recorrido, hago escala y me nutro del pensamiento de diferentes autores que han reflexionado sobre las condiciones sociales y los modos de producción y de organización laboral de los dos últimos siglos.

\section{* Capitalismo y mundo del trabajo}

Las características que tuvieron el concepto de trabajo y los modos de organización laboral en los últimos siglos están en relación directa con las formas que adquirió el capitalismo a través del tiempo. Por lo tanto, haré una rápida caracterización de las fases que atravesó el capitalismo de acuerdo con la exposición que realiza Ernest Mandel en El capitalismo tardío ${ }^{2}$ y que retoma Fredric Jameson en El giro cultural. ${ }^{3}$ Man-

\footnotetext{
${ }^{1}$ Una versión preliminar del presente artículo fue leída en forma de ponencia en las I Jornadas Interdisciplinarias Michel Foucault realizadas en octubre de 2004 en la Facultad de Humanidades (UNNE). Deseo aclarar que este escrito está en relación con la actividad que desarrollo en la cátedra de Antropología Filosófica de la carrera de Relaciones Laborales (UNNE) junto con la profesora Dolores Torres (a quien agradezco sus aportes conceptuales y bibliográficos) y está dedicado a mis abuelos -que fueron obreros- y a mis viejos -que son profesionales-, quienes me transmitieron, de distintos modos, la misma afición y preocupación por el mundo del trabajo.

* Profesor de Filosofía Contemporánea Siglo XIX (UNNE) - e-mail: taton@gmx.net

${ }^{2}$ Cfr.: Mandel, Ernest. El capitalismo tardío. Era, México, 1972.
} 
del divide en tres etapas el desarrollo capitalista: a) capitalismo mercantil; b) capitalismo monopolista, industrial o imperialista; c) capitalismo tardío, multinacional, avanzado o consumista.

El capitalismo mercantil tuvo al comercio (preponderantemente marítimo y con el empleo de violencia y brutalidad) como forma preferente de acumulación de riquezas y dinero, acopio que originó la capitalización consiguiente. Propios de esta etapa son el surgimiento de los grandes puertos, los corsarios y piratas, los mercados y la colonización de territorios situados allende los mares que rodean Europa. Este momento carece de interés para nuestro análisis.

El capitalismo imperialista se caracterizó por el desarrollo productivo del capital acumulado, el cual fue invertido en la agricultura y la manufactura. Aquí el capital se territorializó y convirtió las áreas asociadas a su empleo en centros de producción. Propios de esta época, que tiene a la Revolución Industrial como expresión paradigmática, son las grandes maquinarias, las fábricas que emplean mano de obra asalariada, las condiciones y horarios de trabajo inhumanos, el surgimiento de las metrópolis y el afianzamiento de los dos sectores que serían determinantes en los acontecimientos sociales de la época: burgueses y proletarios. Debido a que esta fase sufrió restricciones en su expansión -impuestas por el alcance limitado de la producción, la distribución y el consumo-, se tuvieron que buscar nuevas formas de acrecentar el capital.

El capitalismo tardío se caracteriza por la búsqueda febril de ganancias ya no a través del descubrimiento de nuevos mercados, sino mediante la concreción de transacciones financieras. El capital se desterritorializa, se separa del contexto concreto de su área de producción, deja de ser dinero del algodón, del trigo o de la fábrica; es el capital financiero o especulativo. Este capital independiente "comenzará a vivir su vida en un nuevo contexto; ya no en las fábricas y los espacios de extracción y la producción, sino en el recinto de la bolsa de valores, forcejeando por obtener una rentabilidad más grande, pero no como una industria que compite con otra rama, y ni siquiera como una tecnología productiva contra otra más avanzada en el mismo rubro de manufacturas, sino más bien en la forma de la especulación misma”. ${ }^{4}$ Propios de esta etapa son, entonces, el capital financiero, las bolsas de valores con sus especulaciones correspondientes, la informatización y la globalización. En la esfera social resalta la paradoja dada entre los rápidos cambios sucedidos en todos los niveles, incomparablemente superiores a los de épocas precedentes, y una estandarización, también nunca presentada, en todos los ámbitos de la vida humana -sentimientos, hábitos de consumo, lenguaje, costumbres, edificaciones, etc.-.

La fase del capitalismo industrial o imperialista tiene su máximo desarrollo en la última mitad del siglo XIX y los inicios del XX. En lo que respecta al mundo del trabajo, este período se distingue por el predominio de una visión moralista del trabajo y por el triunfo del modelo tayloriano o fordista de las organizaciones laborales (denominación que rinde tributo a su precursor teórico -Frederick Taylor- y a quien llevó a cabo cabalmente dicho modelo en sus empresas -Henry Ford) En tanto que el capitalismo tardío o multinacional se impone en las décadas finales del siglo XX y tiene como correlato una visión posmoralista del trabajo y el modelo de organización laboral conocido como postayloriano, de recursos humanos o posburocrático. A su vez, cada etapa y su forma de entender y llevar adelante el trabajo origina lazos sociales diferentes: la

\footnotetext{
${ }^{3}$ Cfr.: Jameson, Fredric. Cultura y capital financiero. En: El giro cultural. Escritos seleccionados sobre el posmodernismo 1983-1998. Trad. Horacio Pons. Manantial, Bs. As., 1999.

${ }^{4}$ Ibíd. p. 188.
} 
primera posee como particularidad ser una sociedad de productores conformada por trabajadores industriales bajo un control social estricto y cercano; a la vez que la segunda se define por ser preponderantemente una sociedad de consumidores con relaciones más atomizadas y específicas entre seres que cumplen diversas funciones sin parámetros tan definidos.

Dedico los próximos dos apartados a desarrollar las características enumeradas en el último párrafo, sus relaciones e implicaciones.

\section{* Disciplinamiento social y laboral del industrialismo del siglo XIX}

Los cambios generados por las revoluciones sociales e industriales llevaron al afianzamiento del capitalismo industrial, lo cual condujo a una producción y acumulación de bienes materiales nunca dadas y a la redistribución espacial y social de esos bienes, lo que originó a su vez nuevas formas de control para evitar disminuciones en el ritmo de producción y el saqueo de las riquezas.

Como analiza Foucault en La verdad y las formas jurídicas ${ }^{5}$, el establecimiento de la sociedad disciplinaria del siglo XIX se basó en los principios de vigilancia, control y corrección de los individuos dentro de las condiciones impuestas por el apogeo del capitalismo industrial, pero no tanto en relación con crímenes que se hubieran cometido sino con el peligro que representaban los vagabundos y desocupados para los bienes y propiedades de la floreciente burguesía. La "criminalidad virtual” de las masas que llegaban a las grandes ciudades en formación sirvió de fundamento para la constitución del conjunto de instituciones que llevaron a cabo la ortopedia social. Esas instituciones (hospitales, reformatorios, prisiones, fábricas, escuelas) tenían por misión disciplinar a sus integrantes dentro de las pautas del nuevo orden social, buscaban integrarlos en posiciones y roles determinados a partir de la sujeción a una estructura de normas estrictas; se daba una paradójica inclusión social por la reclusión en una institución determinada: "si bien los efectos de estas instituciones son la exclusión del individuo, su finalidad primera es fijarlos a un aparato de normalización de los hombres”. ${ }^{6}$

Las instituciones concretaban este propósito, según Foucault, mediante el cumplimiento de 4 funciones: 1) control del tiempo de los individuos: para ajustar el tiempo de los individuos al aparato de producción y así lograr ponerlo en venta en el mercado a cambio de salario; 2) control del cuerpo de los individuos: con el objeto de disciplinar los hábitos de modo tal que los cuerpos adquieran ciertas aptitudes no sólo dentro de las instituciones sino en la vida en general (Ej.: metodicidad rutinaria, higiene sexual, etc.); 3) creación de un poder polimorfo: con el fin de generar derechos sobre los individuos de carácter político, económico y judicial; y 4) producción de un poder epistemológico: para alcanzar un saber nuevo de y sobre los individuos surgido de la observación y control permanente de los internos.

Estas funciones cumplidas por las instituciones en el siglo XIX tuvieron en el ámbito laboral su formulación más cabal, precisa y exitosa en el modelo de administración o racionalización científica del trabajo que Frederick Taylor elaboró y difundió a fines del XIX y principios del XX. La organización tayloriana llevó hasta las últimas consecuencias los aspectos represores y disciplinantes de la institución fábrica con su

\footnotetext{
${ }^{5}$ Cfr.: Foucault, Michel. La verdad y las formas jurídicas. Gedisa, Barcelona, 1986.

${ }^{6}$ Ibíd. p.128. Y agrega renglones abajo: “en consecuencia es lícito oponer la reclusión del siglo XVIII que excluye a los individuos del círculo social a la que aparece en el siglo XIX, que tiene por función ligar a los individuos a los aparatos de producción a partir de la formación y corrección de los productores: trátase entonces de una inclusión por exclusión”.
} 
búsqueda incesante del incremento de la producción y la minimización de los costos a través de la implementación de una estructura vertical de corte militar, la división y mecanización de tareas, la cronometrización y vigilancia permanente de las actividades de los obreros, la adaptación de los movimientos de los trabajadores al ritmo de las máquinas y el principio de que la reducción de tiempo de elaboración por unidad es el modo más directo de incrementar los beneficios del capital. A su vez, estas políticas laborales fueron acompañadas por -o fundamentadas en- una visión negativa del género humano, el cual se encuentra signado por el embrutecimiento, la holgazanería y el hedonismo: según su mirada existe una división natural entre seres capaces de desarrollar tareas creativas y otros que no (estos últimos son mayoría y deben engrosar la fila de trabajadores destinados a realizar labores rutinarias), los hombres tienden innatamente a la haraganería (por lo que deben ser supervisados constantemente y ser eliminada cualquier circunstancia que pueda ser causa de distracción -mecanización-) y considera que el obrero está motivado únicamente por el salario que recibe a cambio de sus tareas (visión del hombre como homo economicus) El saber específico producido por los estudios de tiempo-movimiento dentro de los talleres y el control omnímodo sobre las tareas para lograr mayor eficiencia son muestras paradigmáticas de la aplicación de la ortopedia social sobre los individuos con el objetivo de insertarlos dentro de la maquinaria de producción y de fijarles determinadas conductas juzgadas como apropiadas para el rol que les correspondía dentro del nuevo esquema social. ${ }^{7}$

A pesar de las condiciones denigrantes que reinaban dentro de los recintos laborales, el cambio enorme que supuso la industrialización condujo a que el trabajo asalariado ocupase un lugar central en la vida de los seres humanos y pasara a tener un significado positivo como nunca antes lo había poseído en amplios sectores de la sociedad, lo cual se reflejó en el predominio de una visión moralista del trabajo. Esta concepción se caracterizó por considerar el trabajo como el medio por excelencia para lograr el progreso humano y entronizó su carácter reformador y edificante; a través de la realización de las tareas laborales el individuo forjaba su carácter y se convertía en un ciudadano útil, a la vez que contribuía a la construcción de una nación mejor y retribuía en parte lo que la sociedad le había proporcionado. Lipovetsky describe esta disposición hacia el trabajo de modo adecuado: "la fe en el trabajo civilizador y liberador ocupa el centro del discurso social, la pereza es un "crimen social" que crea un peligro para el que se entrega a él y para la colectividad de la que es miembro, cada uno debe pagar su deuda social y contribuir al desarrollo de la especie humana y de la nación”. ${ }^{8}$

Así el trabajo en el siglo XIX conquista un sitial indiscutido como factor clave para la integración y como fuente de identidad y de derechos sociales. Deja de ser una labor que se realiza en talleres familiares o en territorios bien definidos con poca interacción entre sí y se transforma en una actividad pública que adquiere entidad en tanto es demandada, reconocida y remunerada por otros. El capitalismo industrial objetiva la

\footnotetext{
${ }^{7}$ Cfr.: Hopenhayn, Martín. Repensar el trabajo. Historia, profusión y perspectivas de un concepto. Norma, Bs. As., 2001. cap. VIII. - Rolle, Pierre. Introducción a la sociología del trabajo. Trad. Ramón Zabalza Ramos. Planeta, Barcelona, 1974. cap. II. El modelo tayloriano también representa la concreción más patente dentro de las organizaciones laborales del proceso de alienación que ya había sido descrito por Marx en sus Manuscritos de 1844.

${ }^{8}$ Lipovetsky, Gilles. El crepúsculo del deber. Anagrama, Barcelona, 1994. p. 172. El trasfondo de esta visión moralista del trabajo está en la línea del análisis que realiza Max Weber sobre la intrínseca relación existente entre la exaltación religiosa del trabajo del protestantismo y el afianzamiento del capitalismo en los siglos XVII y XVIII [Cfr.: Weber, Max. La ética protestante y el espíritu del capitalismo. Trad. Luis Legaz Lacamba. Revista de Derecho Privado, Madrid, 1955].
} 
fuerza de trabajo y la pone en circulación en el mercado, por lo tanto el obrero poseedor de esa fuerza- debe acoplarse a ese movimiento económico y no puede permanecer aislado del resto de los integrantes de la sociedad. André Gorz afirma en este sentido que la sociedad industrial se distingue de todas la anteriores por ser una sociedad de trabajadores, en ella por primera vez el trabajo deja de pertenecer a la esfera privada y de ser un factor de exclusión (Ej.: los esclavos en la antigüedad) para convertirse en el agente por el cual se logra el reconocimiento del resto de la comunidad y se consigue una existencia social específica. ${ }^{9}$ A partir de este momento, la comarca, la tradición o el linaje familiar al que uno pertenece ceden su trono como medios de identificación social al trabajo y la profesión.

La configuración social y el lugar que ocupa el trabajo dentro de ella conducen a que la sociedad de esta época se constituya como una sociedad de productores. El énfasis puesto en las actividades productivas que mueven el mundo industrial es superior al que se les otorgaba en períodos precedentes y hace que adquieran mayor importancia que cualquiera de las otras esferas en que se desempeñan normalmente los ciudadanos; Zygmunt Bauman lo expresa del siguiente modo: "aunque la humanidad venga produciendo desde la lejana prehistoria y vaya a hacerlo siempre, la razón para llamar "comunidad de productores" a la primera forma de la sociedad moderna se basa en el hecho de que sus miembros se dedicaron principalmente a la producción; el modo como tal sociedad formaba a sus integrantes estaba determinado por la necesidad de desempeñar el papel de productores, y la norma impuesta a sus miembros era la de adquirir la capacidad y la voluntad de producir". 10

\section{* La reformulación del trabajo en el siglo XX}

Las reformas económicas y sociales producidas por el paso del capitalismo industrial al tardío o neoliberal, descriptas con anterioridad, fueron acompañadas por modificaciones en el ámbito laboral. Es posible sintetizar estos cambios agrupándolos en cuatro grandes ejes relacionados con lo desarrollado en el parágrafo anterior: a) reemplazo de la visión moralista del trabajo por otra posmoralista; b) fin de la hegemonía del modelo tayloriano en las organizaciones laborales y auge de la gestión por recursos humanos; c) redefinición del lugar que ocupa el trabajo en la vida individual y como generador de identidad social; y d) paso, como consecuencia de esto último, de una sociedad de productores a una sociedad de consumidores.

Vamos al primer ítem. En la visión posmoralista del trabajo el carácter de deber social del trabajo es desplazado por una disposición en la que priman los intereses de realización individual. Los ideales colectivos superiores (nación, progreso, etc.) y la solidaridad social, en cuanto motores principales y finalidades de la actividad laboral, son abandonados en favor de instancias personales (búsqueda del bienestar propio) o, cuando mucho, corporativas (beneficio empresarial). Si bien la realización del trabajo nunca se hizo en forma totalmente desinteresada - siempre fue llevada en busca de algún tipo

\footnotetext{
${ }^{9}$ Cfr.: Gorz, André. Metamorfosis del trabajo. Trad. Mari-Carmen Ruiz de Elvira. Sistema, Madrid, 1997. El gran cambio que supuso en la concepción del trabajo el capitalismo industrial del siglo XIX queda sintetizado en la sentencia con que Gorz abre el cuerpo del texto: "lo que nosotros llamamos "trabajo" es una invención de la modernidad. La forma en que lo conocemos, lo practicamos y lo situamos en el centro de la vida individual y social fue inventada y luego generalizada con el industrialismo" (p. 25).

${ }^{10}$ Bauman, Zygmunt. Trabajo, consumismo y nuevos pobres. Gedisa, Barcelona, 2003. p. 44.
} 
de compensación o retribución-, este aspecto utilitarista era acompañado por otros dentro de los discursos predominantes en épocas pasadas o bien no sobresalía de modo tan hegemónico como lo hace en la actualidad. Ahora el trabajo pierde su connotación de obligación social -ya no se plantea como modo de saldar nuestra deuda con la sociedad-, tiene valor en cuanto es el medio para la consecución de metas individuales y avances en el plano material. Es preciso aclarar que si bien el trabajo ya no goza de una valoración tan positiva como en tiempos pretéritos, sigue ocupando un lugar preponderante en la vida y el imaginario de los ciudadanos, pero esta reivindicación se cimienta sobre bases individualistas, consumistas y posmoralistas; va acompañada de expectativas de comodidad, prosperidad y mayor tiempo libre en la esfera privada. El trabajo deja de ser un puente directo hacia la colectividad y se lo vive primordialmente como agente de avance y desarrollo individual.

En lo que hace al segundo aspecto, las organizaciones laborales, bajo el influjo de los cambios políticos, tecnológicos, informáticos y el auge del tercer sector, abandonaron el modelo tayloriano y adoptaron la gestión por recursos humanos. Esta se basa en considerar al empleado como el principal factor de producción y por tratar de que rinda al máximo sin la necesidad de un control permanente sino por la interiorización de los objetivos empresariales. Por lo tanto busca disminuir las instancias burocráticas y tecnocráticas e incentiva la participación, la autonomía individual y el incremento de responsabilidades; pretende sustituir la disciplina piramidal estricta y la división mecánica de tareas por el trabajo en redes y los programas de formación; intenta que los trabajadores no estén atados a un determinado puesto o función sino que sean capaces de afrontar riesgos y situaciones imprevistas (incluso la de convertirse en desempleados y tener que cambiar de ocupación). La motivación psicológica es la nueva fuente de eficiencia y armonía laboral; la presión ya no se orienta tanto hacia las acciones físicas sino a la esfera psicológica de los subordinados: "en la actualidad, la gestión mediante la cultura trata de producir sistemáticamente la adhesión y motivación de los hombres mediante la interiorización de los objetivos de la empresa: el control mecánico del cuerpo tiende a ser sustituido por un "control de las almas" ligero y comunicacional”. ${ }^{11}$ Así este modelo, que parte de la simple premisa que un empleado vigilado rinde menos que uno vigilado y motivado, presenta la responsabilidad como deseable y necesaria para la expansión personal, no sólo busca la disciplina sino también la adhesión emocional de sus integrantes.

Con respecto al tercer ítem, las transformaciones producidas en la situación, concepción y modos de organización del trabajo condujeron a que éste: a) generara consecuencias negativas en el ámbito individual y b) disminuyese su rol de agente de identificación social. En el plano individual, la rápida adaptabilidad que se exige a los trabajadores causa incertidumbre, las reglas cambiantes de hoy provocan ansiedad y debilitan el compromiso mutuo, la flexibilidad en vez otorgar más libertad produce mayor inestabilidad emocional, la inseguridad laboral traslada sus efectos perjudiciales hasta el ámbito individual, familiar y otros círculos cercanos. Richard Sennett afirma al respecto que las condiciones impuestas en el mundo laboral actual dificultan el establecimiento de vínculos sólidos y la consolidación a largo plazo de los rasgos emocionales que conforman el carácter y que conceden estabilidad y unidad a la estructura psíquica: "el capitalismo del corto plazo amenaza con corroer el carácter, en especial aquellos aspectos del carácter que unen a los seres humanos entre sí y brindan a cada uno de ellos una

\footnotetext{
${ }^{11}$ Lipovetsky, Gilles. Op.cit.. p. 176.
} 
sensación de un yo sostenible. (...) Las especiales características del tiempo en el neocapitalismo han creado un conflicto entre carácter y experiencia, la experiencia de un tiempo desarticulado que amenaza la capacidad de la gente de consolidar su carácter en narraciones duraderas". ${ }^{12}$

En cuanto al punto b), el resquebrajamiento de los fundamentos de la sociedad industrial y las transformaciones laborales consiguientes hicieron que los procesos de inclusión social ya no tengan como eje al trabajo y se conviertan en multifacéticos. La posibilidad de generar una identidad continua y coherente se ve desafiada por los avatares que gobiernan el mundo laboral: "sólo en casos muy contados se puede definir (y menos aún, garantizar) una identidad permanente en función del trabajo desempeñado. Hoy, los empleos permanentes, seguros y garantizados son la excepción. (...) Nada perdurable puede levantarse sobre esta arena movediza. En pocas palabras: la perspectiva de construir, sobre la base del trabajo, una identidad para toda la vida ya quedó enterrada definitivamente para la inmensa mayoría de la gente (salvo, al menos por ahora, para los profesionales de áreas muy especializadas y privilegiadas)". ${ }^{13}$ Que el trabajo ya no es tan determinante como proveedor de identidad social tal cual lo era en el siglo XIX queda demostrado en que en la actualidad la pertenencia a un grupo social se da en la mayoría de los casos por compartir intereses o hábitos de consumo similares y no por la tarea laboral que se desarrolla. El reconocimiento no depende exclusivamente de que alguien sea secretario, mecánico o profesor, sino que está en relación también con las actividades extra-laborales que realiza, los lugares de ocio a los que asiste, las creencias que profesa, los tipos de artículos que compra y en los que vuelca detalles de su personalidad (vestimenta, teléfonos celulares, informática, etc.), la afición por tal o cual música, programa de TV o sitio de Internet, etc. ${ }^{14}$

\footnotetext{
${ }^{12}$ Sennett, Richard. La corrosión del carácter. Las consecuencias personales del trabajo en el nuevo capitalismo. Trad. Daniel Najmías. Anagrama, Barcelona, 2000. p. 25 y 30. La tesis central de este texto, expuesta a través de la historia laboral de un padre empleado de limpieza y su hijo ejecutivo, es justamente que las organizaciones empresariales de nuestro tiempo signadas por la avidez de ganancias rápidas, el "capital impaciente”, el reemplazo de puestos de trabajos estables por proyectos temporarios y los cambios en las estructuras laborales (que implican el despido y recambio masivo de personal) vuelven disfuncional el relato que predominaba hasta pasado los mediados del siglo XX de un progreso individual lineal y acumulativo a lo largo de los años, por lo que es sustituido en la actualidad por el lema "nada a largo plazo". Este lema gobierna los emprendimientos capitalistas y se refleja en la esfera personal a través del debilitamiento de la confianza informal, el establecimiento de "vínculos débiles" en los distintos ámbitos (de corta duración y baja intensidad), la falta de apego al sacrificio, la lealtad y el compromiso, y, por último, la corrosión del carácter a la que hace alusión el título del libro. Bauman coincide en lo que respecta al cambio de disposición generado por la búsqueda de satisfacciones inmediatas y lo ejemplifica mediante una comparación entre nuestra sociedad que tiene como ícono las tarjetas de créditos y la de nuestros antecesores que tenía como símbolo las libretas de ahorro, entre una comunidad que busca saciar el deseo aquí y ahora y otra en la que se requería un proceso prolongado antes de hacerlo.

${ }^{13}$ Bauman, Zygmunt. Op.cit. pp. 49-50.

${ }^{14} \mathrm{El}$ retroceso del trabajo como fuente de identificación social queda reflejado en este ejemplo cotidiano: tiempo atrás, ser el mecánico o panadero del barrio confería un status específico y generaba un determinado tipo de reconocimiento dentro de la comunidad; ahora ese individuo, que ha debido bajar las persianas por la competencia de las grandes tiendas o los hipermercados, pierde el rol definido que tenía y se convierte en un sujeto más que toma el colectivo a la mañana para ir a trabajar a otro lugar (o se queda en su casa porque está desempleado). La integración más próxima a su vecindario deberá producirse entonces a través de algún factor extra-laboral y ya no desde su función laboral como sucedía antes.
} 
Esta situación conduce al cuarto y último aspecto nombrado: el reemplazo de la sociedad de productores por una sociedad de consumidores. Aunque antes también existía el consumo como práctica permanente y reconocida, no se presentaba con el grado de exacerbación con que lo hace en la actualidad; y, en cuanto a la otra cara de la moneda, a pesar de que en el presente quienes componen la sociedad siguen siendo seres productores, esta faceta adquiere connotaciones distintas y retrocede pues el énfasis mayor ya no está puesto en ella. Aquello que define a un individuo, en primer lugar, son sus posibilidades y hábitos de consumo; la sociedad se constituye a partir de seres que se guían de acuerdo con lo que sus parámetros de consumo les indican: "el papel -en otros tiempos a cargo del trabajo- de vincular las motivaciones individuales, la integración social y la reproducción de todo el sistema productivo corresponde en la actualidad a la iniciativa del consumidor". ${ }^{15}$ El trabajo pasa a ocupar un lugar subalterno: es considerado como un medio necesario para ingresar al mundo del consumo -pues brinda, a través del salario, la oportunidad de comprar bienes y servicios- antes que como un ámbito que permite el desarrollo de cualidades personales, éticas o culturales; con lo cual pierde su independencia y pasa a ser principalmente un intermediario entre el deseo de consumo y la concreción del deseo (concreción que, como el psicoanálisis nos enseña, nunca alcanzará la satisfacción plena y deseo que, como la mercadotecnia nos muestra, siempre será estimulado por nuevas estrategias y variantes). Además de, y antes que, productores debemos saber desempeñar -y somos entrenados en tal sentido- el rol de consumidores.

\section{* Encrucijada (a modo de conclusión)}

De lo expuesto pueden extraerse dos consecuencias referidas a los conceptos de trabajo aquí analizados, estas reflexiones se concatenan cronológicamente y conducen a una encrucijada que solicita respuesta urgente.

La primera conclusión está referida al concepto de trabajo predominante en el siglo XIX y es más bien una evidencia histórica: existió una postura ambivalente frente al mundo del trabajo producto del auge del industrialismo durante este período y, además, dicha concepción se convirtió en obsoleta debido a las grandes transformaciones ocurridas durante el siglo XX. El carácter regenerador y edificante que se otorgaba al trabajo dentro de la visión moralista del trabajo de la época contrastaba con las condiciones denigrantes en que era llevado a cabo ${ }^{16}$ y con la mecanización y rutinización que

\footnotetext{
${ }^{15}$ Bauman, Zygmunt. Op.cit.. p. 48. Y sostiene más adelante: "la estética del consumo gobierna hoy, allí donde antes lo hacía la ética del trabajo. (...) el trabajo perdió su lugar de privilegio, su condición de eje alrededor del cual giraban todos los esfuerzos por constituirse una identidad. Pero, como camino elegido para el perfeccionamiento moral, el arrepentimiento y la redención, el trabajo dejó de ser, también, un centro de atención ética de notable intensidad” (pp. 56-7).

${ }^{16}$ La jornada laboral se extendía generalmente entre 12 y 14 horas diarias, las tareas que debían realizar los obreros eran repetitivas hasta el hartazgo, cumplidas muchas veces en condiciones inhumanas (sin luz solar, con escasa ventilación, en mala posición corporal, etc.), los niños y jóvenes se veían obligados a trabajar desde edad temprana, la paga era muy baja (apenas alcanzaba para que el grupo familiar sobreviviera) y los obreros carecían de servicios de salud. El debilitamiento corporal y la extenuación provocadas por las largas jornadas de trabajo, junto con la falta de higiene adecuada y de agua potable y la diseminación de enfermedades epidémicas, hacían que la esperanza de vida de los obreros fuera muy reducida y que muchos de ellos debieran trabajar hasta morir antes de los 40 años. Aún no existían legislaciones que regularan el trabajo (o las pocas existentes carecían de valor empírico) y los trabajadores debían aceptar las condiciones laborales que les eran impuestas. Además, el traslado de grandes masas desde el campo hacia las incipientes metrópolis -generado por el reemplazo de la agricultura y el trabajo artesanal por la producción en
} 
condensó de manera paradigmática en el modelo tayloriano de las organizaciones laborales. Esta ambigüedad condujo a que el trabajo fuera al mismo tiempo fuente de exaltación como de alienación: los panegíricos elevados en nombre del trabajo regenerador y motor del progreso chocaban con el modo en que se cumplía fácticamente, las loas flaqueaban y se desvanecían delante de los muros de las fábricas. Igualmente esta ambivalencia no fue impedimento para que sendos aspectos continuaran teniendo vigencia durante décadas dentro de los discursos sociales, uno, y en las prácticas cotidianas, el otro; la pérdida de vigor y caída en desuso de ambos no se debió a estas "inconsistencias internas" sino a los múltiples cambios tecnológicos, sociales y en los modos de producción y organización dados en el siglo XX.

La segunda conclusión tiene que ver, justamente, con las implicaciones teóricas que tienen las transformaciones ocurridas durante la centuria que acaba de finalizar en lo que respecta a la noción del trabajo. El concepto de trabajo que surge en el siglo XX con el desarrollo del capitalismo tardío, por un lado, mantiene la misma posición ambigua que tuvo el industrialismo con respecto al sujeto del trabajo y, por otro, también ha entrado en crisis en las últimas décadas por resultar insuficiente para abarcar el multifacético mundo laboral de hoy.

La actitud de ambivalencia se debe a que aunque tanto la visión posmoralista del trabajo como la gestión por recursos humanos dentro de las organizaciones se proponen como concepciones que contemplan las distintas esferas del ser humano con la intención de promover un desarrollo íntegro y una mayor libertad, en realidad tienden hacia una presión más sutil pero no menos omnipresente que busca afanosamente la minimización de los costes -incluido el factor humano- y que para ello no repara en flexibilizar los horarios de trabajo, imponer la libre adhesión, disimular despidos en masa bajo el eufemismo de reestructuración empresarial, presentar las negociaciones colectivas como atropellos a la libertad individual y como entorpecedoras del normal funcionamiento empresarial, desarrollar un marketing de excelencia a pesar de arremeter contra derechos laborales básicos y otras acciones similares que pueblan el mercado de trabajo actual y que representan formas nuevas y más sofisticadas de deshumanización en el ámbito laboral. Nuevamente predomina un discurso de bonanzas y perfección gracias a las variaciones teóricas y metodológicas introducidas, mientras en la práctica se concretan arbitrariedades y abusos de distinta índole. La coexistencia de estos aspectos tan disímiles representa una continuación, sólo que con pares dicotómicos distintos, de los claroscuros y contradicciones que ya se habían presentado en el siglo XIX en torno del trabajo.

En cuanto al segundo aspecto nombrado, considero que la concepción vigente de trabajo se encuentra en crisis debido a que se origina en el concepto estrecho de trabajo que sostiene el sistema capitalista, para el cual sólo son trabajo las acciones que satisfacen requisitos tales como estar institucionalizadas, cumplir horarios, estar en venta dentro del juego de la oferta y la demanda, realizarse en relación de dependencia o ser profesión liberal reconocida, etc., es decir que quita el reconocimiento a aquellas que no se ajustan a las condiciones y las leyes impuestas por el propio mercado económico. Esta visión niega a numerosas actividades necesarias socialmente el rótulo de "trabajo" y tiene el desmérito de haber logrado, por una parte, que una porción creciente de la población sea considerada desocupada aún cuando ocupe su tiempo con múltiples tareas criar hijos, participar de organizaciones sociales, cocinar, hacer voluntariados, etc.-, con

serie tras la Revolución Industrial- trajo aparejado el establecimiento de estos grupos en sectores reducidos de las ciudades en situación de hacinamiento. 
la consecuente degradación personal, social y económica que ello implica, y, por otra, que muchos de quienes sí poseen trabajo sean sometidos a condiciones que van en desmedro de la salud e integridad individuales y de la realización de mínimas potencialidades propias. La exclusión social generada por la primera situación y la presión contra disciplinamiento de- la población empleada y desempleada causada por la segunda, tienen relación estrecha con esta exigua definición de trabajo. ${ }^{17}$

Debido a las insuficiencias demostradas, sostengo que el concepto de trabajo está en una encrucijada y debe ser reexaminado. Considero que el movimiento inicial para que los planteamientos teóricos no acompañen de modo silencioso y cómplice las prácticas excluyentes y denigrantes que vienen poblando el mundo laboral -en su significado más amplio- consiste en el replanteo de lo que entendemos por trabajo y del valor que éste tiene para la vida individual y para la sociedad; sin una redefinición más comprehensiva, y desobediente de las sentencias apodícticas del mercado, se vuelve imposible cualquier intento de propuesta conceptual potente en sentido regenerativo. ${ }^{18} \mathrm{La}$ ampliación de la noción de trabajo de modo tal que incluya a quienes realizan actividades que no son rentables dentro del esquema capitalista (desempleados) y a quienes se ven obligados a realizar actividades en condiciones impropias debido a la disminución de las plazas rentables dentro de dicho esquema (subempleados) es un paso necesario para poder exigir el reconocimiento social y económico de estas tareas, en pos de bregar por una mayor equidad y una mejor distribución de la riqueza.

Para finalizar, con la intención de que sirva como principio directriz en la elaboración de respuestas a la encrucijada a la que hemos arribado, voy a realizar una breve analogía entre la cuestión tratada aquí y lo que propone Michel Foucault en cuanto a la relación entre poder y verdad. Foucault en la entrevista que cierra la compilación publicada bajo el título de Microfísica del poder sostiene que: "no se trata de liberar la verdad de todo sistema de poder - esto sería una quimera, ya que la verdad es ella misma poder- sino de separar el poder de la verdad de las formas de hegemonía (sociales, económicas, culturales) en el interior de las cuales funciona por el momento". ${ }^{19}$ Según este autor el carácter conflictivo de la verdad nunca debe conducir a la disociación de verdad y poder ya que la primera es sostén del y se sostiene en el poder, intentar desligar ambas esferas es una misión teórica vana -una pasión inútil-; lo que sí es posible, y merece ser intentado por su riqueza teórica y su potencia reveladora, es apartar la verdad de los modos preponderantes de poder en los que se desarrolla y preserva en la actualidad. Pues bien, de modo similar, la solución a las dificultades planteadas por el mundo laboral contemporáneo jamás puede pasar por tratar de separar hombre y trabajo, pero sí hay que intentar desprender el trabajo de las formas sociales y productivas hegemónicas en que los hombres desarrollan hoy sus actividades. Cualquier tentativa de divorcio entre

\footnotetext{
${ }^{17}$ La exclusión social queda plasmada en las circunstancias en que deben realizar, y la desconfianza que suscitan, aquellos que realizan tareas públicas no reconocidas como trabajo genuino: cartoneros, vendedores ambulantes, limpiadores, changarines, etc.. Y la función de las altas tasas de desempleo como factor de disciplinamiento social se evidencia en que la angustiante posibilidad de caer dentro de las cada vez más cuantiosas filas de desempleados, o de no salir de ellas, hace que sean aceptadas hasta las condiciones laborales más serviles y se acallen las voces de reclamo en su contra.

${ }^{18}$ Coincido en esta necesidad de reconceptualizar el trabajo con el interesante y sugestivo análisis que realiza André Gorz en Miserias del presente, riqueza de lo posible [Trad. Cristina Piña. Paidós, Bs. As., 1998].

${ }^{19}$ Foucault, Michel. Microfísica del poder. Trad. Julia Varela y Fernando Álvarez-Uría. La Piqueta, Madrid, 1980. p. 189.
} 
hombre y trabajo es a toda vista conceptualmente inconducente -refutada desde posturas disímiles como, por ejemplo, la antropología marxista ${ }^{20}$ y la Doctrina Social de la Iglesia $^{21}$ - debido a que el hombre tiene inscrita en su humana condición existir como un ser productivo: el género humano debió engendrar distintos tipos de bienes (materiales, simbólicos, etc.) para superar la desventaja física que tiene frente a otras especies y así convertirse en la especie dominante. ${ }^{22}$ El desafío, en cambio, reside en la búsqueda y el planteo de alternativas que tiendan a apartar el trabajo de las formas económicas y de organización abusivas que predominan en la actualidad y que invaden y regulan tanto las instituciones como nuestra más íntima lógica cotidiana, con el propósito de que las condiciones laborales apunten en forma creciente a que la integración del hombre al aparato de producción no se haga desde la óptica dominante del mercado y su directriz de la maximización a cualquier costo, sino desde parámetros más inclusivos. Parafraseando y adaptando la anterior cita foucaultiana a nuestro tema, la máxima orientadora quedaría así: "no se trata de liberar al hombre de todo sistema laboral -esto sería una quimera, ya que el hombre es él mismo, en parte, trabajo- sino de separar el concepto de trabajo de las formas de hegemonía (sociales, económicas, culturales) en el interior de las cuales funciona por el momento”.

\begin{abstract}
El presente artículo se centra en el estudio de las dos concepciones de trabajo predominantes en los siglos XIX y XX. Para ello, en el cuerpo del escrito, se analiza el contexto histórico y social en que surgieron sendos conceptos, se despliegan las características que ambos poseen y se extraen algunas consecuencias que trajeron y traen para los seres humanos en relación con el mundo laboral. En la parte final se presta especial atención a las insuficiencias que presenta la
\end{abstract}

\footnotetext{
${ }^{20}$ Cfr.: Marx, Karl y Engels, Friedrich. La ideología alemana. Trad. Wenceslao Roces. En: Marx, Karl. La cuestión judía y otros escritos. Trad. varios. Planeta-Agostini, Barcelona, 1994. Según los autores el ser humano se diferencia del resto de los animales porque produce sus medios de subsistencia, posibilidad ésta que alcanza gracias a la organización de su grupo social. El hombre llega a ser hombre -como especie- cuando comienza a trabajar, a generar un entorno material diferente del que legó de la naturaleza. El trabajo, por lo tanto, es la actividad productiva específicamente humana; debe ser un acto conciente, voluntario y libre, y no un hecho mecánico tendiente a lograr la mera supervivencia física, y debe consistir en la objetivación de la personalidad de quien lo realiza. A partir de estas premisas, luego Marx analiza el proceso de alienación y degradación humana que generan las condiciones laborales que impone el capitalismo.

${ }^{21}$ Cfr.: Encíclicas Sociales. Mater et Magistra, Pacem in Terris, Populorum Progressio, Igualdad-Participación - Laborem Exercens. Paulinas, Santiago (Chile), 1992. Aquí el trabajo tiene un carácter personal ya que el hombre es el sujeto del trabajo y en éste deben plasmarse las condiciones de creatividad, conciencia y libertad propias del espíritu humano. En la noción cristiana de persona el trabajo ocupa un lugar importante por su característica de ser un modo de expresión de los dones divinos entregados al humano.

${ }^{22}$ Si bien esta faceta productiva del hombre es inseparable de cualquier formación social, se vuelve más patente en el ámbito de los discursos modernos occidentales, una vez acaecida la deflación de la cosmovisión cristiana, con los aportes de la antropología iluminista, en principio, y luego, de manera más explícita, con el empuje de las teorías y planteos que crecieron bajo el influjo del contexto generado por el capitalismo industrial y el ascenso de la burguesía. Es decir que las condiciones de posibilidad (condiciones que son históricas, no trascendentales al modo kantiano) en las que se desenvuelve el trabajo hoy son las que instauro la modernidad, pero de ningún modo son las únicas en las que el hombre puede desarrollar su faz laboral [para ver la perspectiva en que el concepto de condiciones de posibilidad es entendido como un producto histórico que hace posible y fija determinados tipos de conocimientos y prácticas: Foucault, Michel. Las palabras y las cosas. Siglo XXI, México D.F., 1968].
} 
concepción vigente y se intenta esbozar un principio directriz para enfrentar la encrucijada en que dicha noción se encuentra. 